\title{
The role of emerging insulin and regimens in overcoming insulin treatment resistance
}

\author{
Steven H Barag ${ }^{1,2,3,4 *}$, Talin Meshefedjian ${ }^{5}$ and Kevin Diep ${ }^{5}$ \\ ${ }^{1}$ Aureus Medical Group, Inc., Nebraska, USA \\ ${ }^{2}$ Western University College of Osteopathic Medicine, California, USA \\ ${ }^{3}$ Touro University College of Osteopathic Medicine, California, USA \\ ${ }^{4}$ San Antonio Regional Hospital, California, USA \\ ${ }^{5}$ OMS IV, Western University College of Osteopathic Medicine, California, USA
}

\section{Introduction}

Type 2 diabetes (type 2 diabetes) is the most common type of diabetes in adults, known for its broad variability in insulin deficiency and resistance. The growing prevalence of type 2 diabetes has a direct relationship with increasing degrees of obesity. Initially, the control of hyperglycemia is attempted with metformin, along with lifestyle modifications. Regardless of initial therapy success, the majority of patients are unable to sustain appropriate glycemic control. Despite strong resistance by both physicians and patients, insulin is indicated for long-term glycemic control in type 2 diabetes. The oral agents typically used become less effective with the decline of beta cell function. It is important to educate patients on the disease's progressive nature and to present insulin as an appropriate medical treatment, as to avoid perpetuating the negative stigma insulin has developed. Major advancements have been made in the field of insulin in order to achieve desired pharmacokinetic properties and reduce adverse effects. With the development of insulin analogs by modifying the structure of insulin, it now has a long duration of action of over 24 hours, exhibits minimal variability, sustains serum concentrations without peaks or troughs, and ensures safety and tolerability. Based on these improvements, there will be much less resistance to the implementation of insulin in type 2 diabetes management.

Data shows that more than $25 \%$ of patients may refuse insulin therapy once it is prescribed. Patients often have psychological insulin resistance and studies show that clinical presentation of this resistance may point to a single issue such as a fear of needles. It can also present with more complexity, involving the patient's belief about the meaning of insulin therapy, poor self-efficacy concerning the skills needed for insulin therapy, and lack of appropriate information. It is vital to overcome these barriers by questioning patient knowledge of insulin treatment and their preconceived perceptions or fears. Most of these new formulations eliminate the common concerns that deter patients from starting or continuing insulin treatment, and that keep physicians from presenting insulin early on as an appropriate and effective treatment for type 2 diabetes.

\section{Insulin Degludec}

Insulin degludec is an ultra long-acting insulin analog, which possesses a glutamic acid spacer linking a 16-carbon fatty di-acid chain in the place of the threonine at the B30 position in human insulin [1]. This allows a stable di-hexameric structure, in contrast to the hexameric human insulin. The structural property of the analog allows a slow and stable absorption of the insulin, independent of blood perfusion at the injection site. It also allows long-acting, consistent delivery of the drug [2]. Studies show a half-life of 25.4 hours, and a total duration of 42 hours [3]. Once steady-state concentration is achieved in three days, the concentration does not waver. This is in contrast to available basal insulin, which exhibits a peak and trough. Insulin degludec has minimal variability, unlike glargine, which has a higher concentration in the first 12 hours, and diminished concentration in the following 12 hours post administration [4]. Insulin degludec was found to be equally distributed, with $25 \%$ in each quarter of the day, upon 24-hour pharmacodynamic profile analysis [5]. This even distribution with one administration of insulin provides simplicity and is significantly less daunting to those who perceive insulin therapy as being complicated.

Studies by regulatory bodies such as the Food and Drug Administration (FDA) show that degludec is associated with a lower incidence of confirmed hypoglycemia, as well as a reduction of nocturnal glycemia [6]. Studies have also shown that fixed time and flexible degludec regimens have similar efficacy and safety, affording flexibility to patients concerning time of administration [7]. This increases patient compliance to treatment, as it makes therapy less complex and demanding. Degludec can be used as both basal and basal-bolus therapy, in both types of diabetes mellitus.

\section{Insulin Glargine U300}

Approved by the US FDA in 2015, Insulin glargine U300 (Gla300 ) is a more concentrated formulation of insulin glargine U100 (Gla-100), which allows longer duration of action and less variability in concentration. It differs from human insulin structurally by the addition of two arginine molecules after position B30 and placement of glycine in the place of asparagine at position A21 [8]. This allows for the formation of a microprecipitate in the subcutaneous injection site, permitting slow, prolonged release. At steady state, Gla-300 is more stable compared to Gla-100, with a half-life of 18-19 hours, independent of dose, and glucose lowering activity for up to 36 hours [8].

Correspondence to: Steven H. Barag, 4794 Haven Ave. \#250 Rancho Cucamonga CA, 91730 USA, Tel: (909) 240-5285; E-mail: drbarag@gmail.com

Received: October 25, 2017; Accepted: November 28, 2017; Published: December 04, 2017 
Randomized controlled clinical studies have shown that Gla300 has comparable efficacy to that of Gla-100, but with less risk of hypoglycemia [9]. A meta-analysis of randomized clinical trials demonstrated a $31 \%$ lower relative difference in the annualized rate of nocturnal hypoglycemic events over a six-month period for Gla300 compared to Gla-100 [10]. This is significant, as hypoglycemic episodes are associated with diminished work productivity and increased, avoidable healthcare utilization. The costs of hypoglycemia secondary to insulin treatment are estimated to be about $\$ 2,000$ per person, annually. A study shows that nocturnal hypoglycemic events are associated with increased self-monitoring of glucose, and about $15 \%$ of the patients reduced insulin dosage to prevent reoccurrence, which can be detrimental to long term, overall glycemic control [11].

Similar to insulin degludec, Gla-300's long duration of action enables flexible dosing, while maintaining efficacy and safety. Patient non-compliance to medication is highly attributable to the complexity and burden of the treatment. Frequency of administration is inversely related to compliance. A less restricted regimen with the same results will increase patient cooperation and increase quality of care. In a study comparing flexible dosing ( $24+/$ - up to three hours) and fixed dosing ( 24 hours) over a 12 week period, measuring efficacy with the change in hemoglobin A1C, changes in fasting blood glucose and daily insulin doses, administration with the flexible dosing time of within a three hour window before or after 24 hours of the last dose had no effect on glycemic control and incidence of hypoglycemia [12].

\section{GLP-1 Agonist/Basal Insulin Combination}

On November 21, 2016, the US FDA approved an insulin glargine/ lixisenatide 100 units $/ \mathrm{mL}$ and $33 \mathrm{mcg} / \mathrm{mL}$ combination injectable for the treatment of type 2 diabetes inadequately controlled on basal insulin or lixisenatide. This therapy has been offered as a once-daily injectable.

In 2016, the efficacy and safety of iGlarLixi was studied. Patients receiving iGlarLixi reached an average hemoglobin A1c of $6.9 \%$ versus $7.5 \%$ in the group that received iGlar. Patients receiving the iGlarLixi also had a mean body weight decline by $0.7 \mathrm{~kg}$ compared to an increase of $0.7 \mathrm{~kg}$ with iGlar. Symptomatic hypoglycemia with a blood sugar of $<70 \mathrm{mg} / \mathrm{dL}$ was comparable between both groups [13].

The US FDA also approved an insulin/GLP-1 agonist combination with insulin degludec/liraglutide 100 units $/ \mathrm{mL}$ and $3.6 \mathrm{mg} / \mathrm{mL}$ for the treatment of type 2 diabetes patients who are inadequately controlled on basal insulin or liraglutide.

Studies conducted regarding dual treatment with degludec and liraglutide have demonstrated efficacy in lowering hemoglobin A1c, reducing weight gain, while demonstrating similar adverse events to insulin glargine [14].

Weight gain is a prominent deterrent for diabetic patients. Type 2 diabetics are highly encouraged to lose weight and have an optimal BMI, so it does not seem logical to patients to be taking a medication that is contradictory. This combination injectable, along with the other new insulin formulations, maintains weight, or may even potentially cause weight loss in some patients, which would make them more inclined to follow the treatment plan.

The single-dose injection delivery system of these GLP-1 agonist/ basal insulin combinations provides convenience for hyperglycemic management. Rather than scheduling timing of insulin injections along with oral medications, this regimen only requires a single daily dose in the morning. The reduction in frequency and complexity of diabetic management will allow for improvements in patient compliance to diabetic management.

\section{Discussion and Conclusion}

The prevalence of in the US population continues to rise and is a major cause of blindness, kidney failure, heart attacks, stroke, and amputations [15]. Though insulin remains the most effective treatment for glycemic control in type 2 diabetics, patients are reluctant to start insulin. The number of individuals requiring management of type 2 diabetes will also continuously rise. With the problems faced with modern day treatment such as patient resistance to insulin therapy, inadequate glycemic control, risks of hypoglycemia, and weight gain, controlling this chronic disease will be difficult [16]. The pharmaceutical market has been responsive to patient insulin non-compliance with the expansion of insulin analogs in recent years [17]. The development of new insulin and insulin/GLP-1 agonist combinations provide possible alternatives to the traditional management of hyperglycemia in type 2 diabetes.

The advances in needle technology implemented in these new therapeutic regimens may improve patient compliance. The traditional use of hypodermic needles has been widely unpopular due to anxiety, pain, and needle phobia [18]. The development of shorter and narrower needles has helped in alleviating injection discomfort [19] and can reduce pain and increase patient compliance [20].

With the reduced risk of hypoglycemia and weight loss seen in basal insulin/GLP-1 agonist combinations, patient adherence to insulin therapy may improve and allow for proper glycemic control. The development of novel insulin therapies for type 2 diabetes make this an exciting time for resolving the issues physicians and patients have faced with the active avoidance of insulin treatment in the management of this progressive and ubiquitous disease [21].

\section{Author Contributions}

S.B. wrote the manuscript and researched data. T.M and K.D. researched data.

\section{Guarantor statement}

Dr. Steven Barag is the guarantor of this work and, as such, had full access to all the data in the study and takes responsibility for the integrity of the data and the accuracy of the data analysis.

\section{References}

1. Mathieu C, Hollander P, Miranda-Palma B, Cooper J, Franek E, et al. (2013) Efficacy and safety of insulin degludec in a flexible dosing regimen vs. insulin glargine in patients with type 1 diabetes (BEGIN: Flex T1): a 26-week randomized, treat-to-target trial with a 26-week extension. J Clin Endocrinol Metab 98: 1154-1162. [Crossref]

2. Nishimura E, Rensen AO, Falckhansen BO, Stidsen C, Olsen GS, et al. (2012) Insulin degludec is a new generation ultra-long acting basal insulin designed to maintain full metabolic effect while minimizing mitogenic potential. American Diabetes Association (ADA) 70th Scientific Sessions: Abstract 1406-P.

3. Shah ND, Mullan RJ, Breslin M, Yawn BP, Ting HH, et al. (2010) Translating comparative effectiveness into practice: the case of diabetes medications. Med Care 48: S153-158. [Crossref]

4. Heise T, Hermanski L, Nosek L, Feldman A, Rasmussen S, et al. (2012) Insulin degludec: four times lower pharmacodynamic variability than insulin glargine under steady-state conditions in type 1 diabetes. Diabetes Obes Metab 14: 859-864. [Crossref]

5. Kurzhals P, Heise T, Strauss HM, Bøttcher SG, Granhall C, et al. (2011) Multi-hexamer formation is the underlying mechanism behind the ultra-long glucose-lowering effect of insulin degludec. Diabetes 60: LB12. 
6. Birkeland KI, Home PD, Wendisch U, Ratner RE, Johansen T, et al. (2011) Insulin degludec in type 1 diabetes: randomized controlled trial of a new-generation ultra-longacting insulin compared with insulin glargine. Diabetes Care 34: 661-665. [Crossref]

7. Steinstraesser A, Schmidt R, Bergmann K, Dahmen R, Becker RH (2014) Investigational new insulin glargine $300 \mathrm{U} / \mathrm{ml}$ has the same metabolism as insulin glargine $100 \mathrm{U} / \mathrm{ml}$. Diabetes Obes Metab 16: 873-876. [Crossref]

8. Ritzel R, Roussel R, Bolli GB, et al. (2015) Patient level meta-analysis of the EDITION 1,2 , and 3 studies: glycaemic control and hypoglycaemia with new insulin glargine 300 $\mathrm{U} / \mathrm{ml}$ versus glargine $100 \mathrm{U} / \mathrm{ml}$ in people with type 2 diabetes. Diabetes Obes Metab 17: 859-867. [Crossref]

9. Brod M, Wolden M, Christensen T, et al. (2013) Understanding the economic burden of non severe nocturnal hypoglycemic events: impact on work productivity, disease management, and resource utilization. Value Health 16: 1140-1149. [Crossref]

10. Matsuhisa M, Koyama M, Cheng X, Sumi M, Hirose T (2015) Sustained glycemic control and less nocturnal hypoglycemia with new insulin glargine $300 \mathrm{U} / \mathrm{mL}$ compared with glargine $100 \mathrm{U} / \mathrm{mL}$ over 12 months in Japanese people with T1DM (EDITION JP 1). Diabetes 64: A250.

11. Yki-Järvinen H, Bergenstal RM, Bolli GB, Ziemen M, Wardecki M, et al. (2015) Glycaemic control and hypoglycaemia with new insulin glargine $300 \mathrm{U} / \mathrm{mL}$ versus insulin glargine $100 \mathrm{U} / \mathrm{mL}$ in people with type 2 diabetes using basal insulin and oral antihyperglycaemic drugs: the EDITION 2 randomized 12-month trial including 6-month extension. Diabetes Obes Metab 17: 1142-1149. [Crossref]

12. Riddle MC, Bolli GB, Home PD, et al. (2016) Efficacy and safety of flexible versus fixed dosing intervals of insulin glargine $300 \mathrm{u} / \mathrm{mL}$ in people with type 2 diabetes. Diabetes Technol Ther 18: 251-257. [Crossref]
13. Aroda VR, Rosenstock J, Wysham C, Unger J, Bellido D, et al. (2016) Efficacy and Safety of LixiLan, a Titratable Fixed-Ratio Combination of Insulin Glargine Plus Lixisenatide in Type 2 Diabetes Inadequately Controlled on Basal Insulin and Metformin: The LixiLan-L Randomized Trial. Diabetes Care 39: 1972-1980. [Crossref]

14. Buse JB, Vilsbøll T, Thurman J, Blevins TC, Langbakke IH, et al. (2014) Contribution of liraglutide in the fixed-ratio combination of insulin degludec and liraglutide (IDegLira). Diabetes Care 37: 2926-2933. [Crossref]

15. World Health Organization (2016) Global Report on Diabetes, Geneva.

16. Peyrot M, Rubin RR, Lauritzen T, Skovlund SE, Snoek FJ, et al. (2005) Resistance to insulin therapy among patients and providers: results of the cross-national Diabetes Attitudes, Wishes, and Needs (DAWN) study. Diabetes Care 28: 2673-2679. [Crossref]

17. Gough SC, Jain R, Woo VC (2016) Insulin degludec/liraglutide (IDegLira) for the treatment of type 2 diabetes. Expert Rev Endocrinol Metab 11: 7-19. [Crossref]

18. Hanas R (2004) Reducing injection pain in children and adolescents with diabetes: review of indwelling catheters. Pediatr Diabetes 5: 102-111. [Crossref]

19. Aronson R (2012) The role of comfort and discomfort in insulin therapy. Diabetes Technol Ther 14: 741-747. [Crossref]

20. Gill HS, Prausnitz MR (2007) Does needle size matter? J Diabetes Sci Technol 1: 725-729. [Crossref]

21. Marín-peñalver JJ, Martín-timón I, Sevillano-collantes C, Del cañizo-gómez FJ (2016) Update on the treatment of type 2 diabetes mellitus. World J Diabetes 7: 354-395. [Crossref]

Copyright: $(2017$ Barag SH. This is an open-access article distributed under the terms of the Creative Commons Attribution License, which permits unrestricted use, distribution, and reproduction in any medium, provided the original author and source are credited. 